-Colégio Politécnico da UFSM, Santa Maria - RS

Revista de Gestão e Organizações Cooperativas - RGC

RGC - Santa Maria, RS, v.3, n.5, jan./jun. 2016

ISSN: 2359-0432

DOI: $10.5902 / 2359043219807$

\title{
Diferenciais do Sistema Cooperativo Sicredi: análise das demonstrações financeiras nos anos de 2012 a 2014
}

\author{
Differentials of the Sicredi Co-op System: analysis of financial statements in the years \\ 2012 to 2014
}

\begin{abstract}
Resumo
A concessão de crédito no Brasil ainda é uma realidade multifacetada e, para suprir a necessidade de capital no mercado, aparecem iniciativas populares que têm, continuamente, se destacado na economia mundial, entre elas o foco deste artigo: cooperativas de crédito. O cooperado é, ao mesmo tempo, cliente, dono e fornecedor da cooperativa. Devido a essa capilaridade, questiona-se se é possível avaliar uma cooperativa por meio de indicadores tradicionais. Utilizando pesquisas bibliográficas, o objetivo deste artigo fora avaliar a estrutura de capital do Sistema Cooperativo Sicredi, analisando sua flexibilidade na gestão e sua proximidade com o cooperado $e$, consequentemente, seu impacto nos indicadores de rentabilidade, solvência e de endividamento. É possível concluir que por ser uma instituição diferenciada, merece também uma interpretação diferenciada de seus indicadores, assim, sua forma de captação e de aplicação de recursos favorece o crescimento contínuo de sua margem de rentabilidade sob os serviços oferecidos tornando-o um sistema eficiente de cooperativismo.
\end{abstract}

Palavras-chave: Cooperativa de crédito; crédito; estrutura de capital; análise; indicadores.

\begin{abstract}
The granting of credit in Brazil is still a multifaceted reality and, to meet the need of capital in the market, appear popular initiatives that have continually excelled in world economy, including the focus of this article: credit unions. The member is, at the same time, customer, supplier and owner of the cooperative. Due to this capillary, questions whether it is possible to evaluate a cooperative through traditional indicators. Using bibliographic research, the purpose of this article out to assess the capital structure of the Sicredi Co-op System, analyzing its flexibility in management and its proximity to the member and, consequently, its impact on profitability and solvency indicators of indebtedness. It can be concluded that for being a distinguished institution, also deserves a different interpretation of their indicators, thus his way of capturing and applying resources favors the growth continuum of its margin of profitability under the services offered making it an efficient system of cooperatives.
\end{abstract}

Keywords: Credit union; credit; capital structure; analysis; indicators.

Recebido: 05/10/2015 Aceito: 03/03/201

Ariane Saraiva de Jesus ${ }^{1}$ e Carla Letícia de Almeida ${ }^{2}$

1 Faculdade de Tecnologia de Bragança Paulista, Tecnóloga em Gestão Financeira - nanesaraiva@ hotmail.com - Rua Exp. Luiz

Caetano de Moura, 285, Jd. Vista Alegre, Bragança Pta. -SP - CEP: 12922-424

2 Faculdade de Tecnologia de Bragança Paulista, Tecnóloga em Gestão Financeira - carlaleticia.gf@gmail.com 


\section{Introdução}

$\mathrm{O}$ custo elevado na oferta de crédito, eventualmente, exclui grande parte das pessoas físicas e de empreendedores de pequeno ou médio porte dos serviços financeiros tradicionais que, muitas vezes, sem planejamento, assumem empréstimos a taxas discrepantes e complicam ainda mais seu orçamento. Aproveitando-se desse êxodo, o mercado cooperativista tem se destacado mundialmente pelas ofertas de crédito diferenciado.

A cooperativa apresenta um modo singular de intermediação financeira. As características únicas de seu modus operandi impossibilitam a comparação com outras instituições financeiras. Desse modo, a premissa deste artigo não é comparar ou associar a cooperativa com as demais instituições tradicionais, haja vista que seu propósito e posicionamento estratégico são heterogêneos.

A análise de desempenho de instituições financeiras é realizada por meio de indicadores que buscam evidenciar, em sua grande maioria, o crescimento de seu lucro. Uma vez que as cooperativas não visam ao lucro, alguns indicadores poderiam se tornar ineficientes quando aplicados à cooperativa. Portanto, antes de considerar a eficácia de uma cooperativa por meio de estudos tradicionais, é preciso avaliar se a cooperativa, como uma instituição financeira diferenciada, é passível de estudo por meio desses indicadores.

Objetivo deste artigo é analisar como o modo singular de trabalho das cooperativas influencia no seu contínuo crescimento, em determinado intervalo de tempo, por meio do estudo de suas características e da evolução positiva de seus indicadores financeiros.

Este artigo originou-se da percepção do desenvolvimento do sistema cooperativista no mercado financeiro ao longo dos anos. A introdução de um modo diferenciado de trabalho, em um sistema conformado de padrões preestabelecidos, gera novos meios de gestão que devem ser estudados e aprimorados com o tempo, visando não apenas ao crescimento da empresa, mas também ao de seus associados.

Este artigo se dissipa em cinco seções: a presente introdução; a revisão teórica, base para fundamentação do trabalho; a análise demonstrativa que explana a metodologia adotada (no caso, a pesquisa bibliográfica e análise de demonstrações financeiras), e os resultados obtidos; e por fim, a conclusão desse estudo que aborda as principais descobertas realizadas.

Ao longo deste artigo serão apresentados os conceitos que fundamentam a constituição de uma cooperativa, assim como as análises realizadas em seus resultados financeiros nos períodos de 2012, 2013 e 2014.

\section{Referencial teórico}

Baseado na ideia do coletivismo alavancado à sobrevivência, em 21 de dezembro 1844, em Rochdale, na Inglaterra, como decorrência da Revolução Industrial, um grupo de tecelões se organizou para garantir a produção e o consumo da lã, alterando sua perspectiva de inserção econômica (PINHEIRO, 2008, p. 7). A partir disso, o cooperativismo ganhou forma e conceito, além de diversas aplicações, como na educação, na saúde, nas finanças, no agronegócio, na indústria, no trabalho, entre outras.

O Serviço Brasileiro de Apoio às Micro e Pequenas Empresas, SEBRAE, (2010, p. 8) conceitua o cooperativismo da seguinte forma: "Cooperativismo é o instrumento pelo qual a sociedade se organiza, através de ajuda mútua, da colaboração, da solidariedade, para resolver diversos problemas relacionados ao seu dia-a-dia. As pessoas associadas a uma cooperativa se obrigam, reciprocamente, a contribuir com bens ou serviços para o exercício de uma atividade econômica, de proveito comum, sem objetivo de lucro".

$\mathrm{Na}$ natureza, observa-se o cooperativismo entre espécies que vivem em grupos como os pinguins, as abelhas e, o exemplo mais tradicional, as formigas. Nesses nichos, o indivíduo é parte de uma comunidade e tem responsabilidades para com o bem comum. Seja na colmeia ou no formigueiro, as contribuições de cada um garantem a sobrevivência de toda a espécie (SEBRAE, 2010).

Atualmente, embora o tema cooperativismo integre uma ampla cadeia de publicações acadêmicas, pouco se sabe sobre o que é "ser cooperativista" de fato. Pinheiro (2008, p. 8) enfatiza que: "apesar do potencial de crescimento do segmento no Brasil e da importância que vem adquirindo, é grande o desconhecimento sobre cooperativismo de crédito em nosso país". Para Cardoso (2014, p. 11), um dos maiores benefícios trazidos pelas cooperativas é 
"colocar os produtos e serviços de seus cooperados no mercado, em condições mais vantajosas do que eles teriam isoladamente", enquanto Soares e Melo Sobrinho (2008, p. 69) conceituam: "Por representar iniciativas dos próprios cidadãos, contribui de forma relevante para o desenvolvimento local sustentável, especialmente nos aspectos de formação de poupança e de financiamento de iniciativas empresariais que trazem benefícios evidentes em termos de geração de empregos e de distribuição de renda".

Na obra de Adam Smith, A Riqueza das Nações, de 1776 , o pai da economia atribui que a capacidade de produção baseia-se na divisão do trabalho e na acumulação de capital, uma realidade das cooperativas. Mas Adam Smith também deixa claro que as pessoas não ajudam umas às outras por mera bondade, mas por interesses pessoais. No modelo cooperativista, a capacidade de produção só se torna eficiente se esses interesses forem compartilhados por todos os cooperados e se, por meio da união, puderem gerenciar os recursos, evidenciar habilidades e se desenvolver coletivamente por meio do rateio das despesas inerentes à atividade organizacional.

Para Cardoso (2014, p. 25), “a principal vantagem é possibilitar que indivíduos isolados e, por isso mesmo, com menos condições de enfrentar $\mathrm{o}$ mercado, possam aumentar sua competitividade e, com isso, melhorar sua renda ou sua condição de trabalho". Por isso, o cooperativismo de crédito tem se destacado no sistema financeiro brasileiro, que, contrariamente a outros países, não tem uma cúpula única para este serviço (PINHEIRO, 2008, p. 15). Soares e Balliana (2009, p. 19) salientam que o cooperativismo brasileiro está estruturado em três níveis hierárquicos: "No primeiro, atuam as cooperativas singulares, prestando serviços diretamente aos seus associados; no segundo, atuam as cooperativas centrais, organizando, em maior escala, os serviços econômicos e assistenciais de interesse das cooperativas singulares filiadas, a fim de integrar e orientar suas atividades, bem como facilitar o uso recíproco dos serviços; e no terceiro, atuam as confederações, que orientam e coordenam as atividades das cooperativas centrais".

De acordo com a Lei do Cooperativismo (Lei $\mathrm{n}^{\circ}$ 5.764/71), as cooperativas de crédito são definidas como instituição financeira não sujeita à falência, porém, mesmo se equiparando - conforme a Lei $\mathrm{n}^{\circ}$ 4.595/74, ou Lei da Reforma Bancária - ou prestando serviços semelhantes, as cooperativas de crédito apresentam diferenças em relação às instituições bancárias: o capital social da cooperativa de crédito é composto por quotas-parte e, conforme artigos 24 e seguintes da Lei $\mathrm{n}^{\circ} 5.764 / 71$, seu valor unitário não poderá ser superior ao maior salário mínimo vigente no País, podendo também sofrer estipulações para pagamentos em prestações periódicas; nenhum cooperado ou associado poderá subscrever mais de $1 / 3$ (um terço) do total das quotas-parte, e a principal diferença é que as cooperativas não visam ao lucro. Seus resultados, no caso positivo, denominam-se "sobras", ou "perdas", no caso negativo.

A Receita Federal (2005) apresenta a seguinte definição de sobras: "Na linguagem cooperativa, o termo sobras líquidas designa o próprio lucro líquido, ou lucro apurado em balanço, que deve ser distribuído sob a rubrica de retorno ou como bonificação aos associados, não em razão das cotas-parte de capital, mas em consequência das operações ou negócios por eles realizados na cooperativa".

O crédito cooperativo tem crescido no Brasil e no mundo (PINHEIRO, 2008, p. 7), não só por ofertar serviços mais baratos que as instituições bancárias tradicionais, mas por oferecer ao cooperado toda a seguridade das operações de crédito com orientação antes, durante e depois da concessão. Atualmente, a estrutura cooperativista de crédito brasileira se dispõe da seguinte forma: 1106 cooperativas singulares; 37 cooperativas centrais; 4 confederações e 2 bancos cooperativos (FARIA et al., 2015, p. 28).

Conforme Faria et al. (2015, p. 28), Matias et al. (2014, p. 202), Pinheiro (2008, p. 15), Cardoso (2014, p. 7-12), entre outros autores, as cooperativas de crédito singulares são formadas por um número mínimo de 20 associados; as centrais ou federações são constituídas por, no mínimo, três cooperativas singulares e uma confederação de cooperativas abrange no mínimo três centrais ou federações.

Verifica-se que as cooperativas de crédito ocupam um espaço significativo no contexto econômico por atuarem de forma preponderante com as mais variadas classes, sem objetivo de lucro, mas visando amenizar as dificuldades de contexto financeiro de seus cooperados. Esses cooperados são ao mesmo tempo clientes, fornecedores e principalmente donos do negócio, por isso existe uma dificuldade em se distinguir o capital próprio do capital de terceiros.

Neste artigo, buscou-se evidenciar as singularidades e magnitudes do cooperativismo no Brasil, por meio dos indicadores e da estrutura de 
capital de um dos maiores sistemas cooperativistas do país, o Sistema Sicredi.

\subsection{Sistema Sicredi}

Fundado por alemães em 1902, em Nova Petrópolis, Rio Grande do Sul, foi a primeira cooperativa de crédito do Brasil e da América Latina. O modelo cooperativista adotado foi de Friedrich Wilhem Raiffeisen, conhecido por modelo Raiffeisen, cujas características são: a responsabilidade solidária, a não obrigatoriedade de subscrição e a integralização de capital, a fiscalização rigorosa da administração, a gestão democrática e a indivisibilidade do fundo de reserva (FUNDAÇÃO SICREDI, 2010, p. 3-7).

Atualmente, o Sicredi tem aproximadamente três milhões de associados, sendo $90 \%$ de pessoas físicas - $69 \%$ do meio urbano e $21 \%$ do meio rural - e $10 \%$ de pessoas jurídicas (SISTEMA SICREDI, 2015a). Os associados desse sistema cooperativo estão distribuídos entre as 98 cooperativas afiliadas aliadas a quatro centrais.

Conforme o Relatório de Sustentabilidade de 2014 (SISTEMA SICREDI, 2015b, p. 9), todas as cooperativas singulares, as cooperativas centrais, a Fundação Sicredi, o Sicredi Fundos Garantidores e demais entidades que integram o Sistema Sicredi compartilham serviços prestados pela Confederação Sicredi, que tem a função de avaliar e manifestar-se sobre questões de auditoria interna e externa.

Já o Banco Cooperativo Sicredi, primeiro banco cooperativo brasileiro, é a porta de acesso das cooperativas de crédito ao mercado financeiro e programas especiais de financiamento. Ele administra em escala os recursos e desenvolve os produtos corporativos, as políticas de comunicação, o marketing, a gestão de pessoas e, principalmente, a gestão de riscos. Tem como parceiros estratégicos o Rabobank e a Corporação Financeira Internacional (IFC) e controla empresas de administração de cartões, de consórcios, de bens e de seguros (Sistema Sicredi, 2015b, p. 9).

Vale ressaltar que todo o Sistema Cooperativo é controlado pela Holding Sicredi, que coordena as decisões estratégicas do Sistema, visando propiciar a participação direta e formal das cooperativas de crédito na gestão corporativa e dar maior transparência à estrutura de governança, sendo responsável pelo monitoramento e pelo cumprimento dos deveres legais e estatutários da administração, isto é, o conselho fiscal (SISTEMA SICREDI, 2015b, p. 9).

Para a escolha pelo Sistema Sicredi, ponderou-se, além dos resultados financeiros, a participação territorial e principalmente sua característica de livre adesão a cooperados, isto é, qualquer indivíduo pode associar-se, desde que se identifique e aceite os objetivos da cooperativa (SEBRAE, 2010).

Os resultados utilizados foram obtidos no sítio do Bacen e nos relatórios dos anos de 2012 a 2014 das Demonstrações Financeiras consolidadas do Sistema Sicredi, que, até abril de 2015, compunha-se de 98 cooperativas de crédito singulares, quatro cooperativas centrais, uma confederação e um banco cooperativo. Estes dados possibilitaram a mensuração dos principais indicadores de estrutura de capital que, aliados a pesquisas bibliográficas, serviram para identificar se a estrutura de capital das cooperativas apresenta solidez financeira.

\section{Análise demonstrativa}

O acesso ao crédito e a serviços financeiros proporcionados pelas cooperativas de crédito foram avaliados por meio de indicadores e de pesquisas bibliográficas. Utilizou-se de indicadores de solvência, que evidenciam os recursos próprios de instituição, de indicadores de rentabilidade, que destacam a capacidade de geração de riqueza e valor de instituição, de indicadores de endividamento, que mensuram o autofinanciamento da empresa, e de indicadores de estrutura de capital, que são fontes de financiamento determinantes para decisões de investimento (ASSAF NETO, 2012).

Conforme Pizzani et al. (2012, p. 54), a pesquisa bibliográfica "é um trabalho investigativo minucioso em busca do conhecimento e base fundamental para o todo de uma pesquisa". Por isso, este artigo enquadrase em um estudo de caso com caráter quantitativo, já que foram analisados os relatórios anuais do Sistema Cooperativo Sicredi correspondentes aos exercícios de 2012, 2013 e 2014. A análise financeira é ressaltada por Silva (2012, p. 23) como “(...) uma ferramenta que nos auxilia na avaliação de empresa. A contabilidade é a linguagem dos negócios e as demonstrações contábeis são os canais de comunicação que nos fornecem dados e informações para diagnosticarmos o desempenho e a saúde financeira de empresa. (...) A análise financeira precisa ter um enfoque holístico, abrangendo a 
estratégia de empresa, suas decisões de investimento e de financiamento e suas operações".

Como Oscar Wilde $(2012$, p. 39) já relatava na obra $O$ retrato de Dorian Gray, de 1890: "Hoje em dia, as pessoas sabem o preço de tudo, mas não sabem o valor de nada". Por isso, é importante ressaltar que a avaliação do desempenho de qualquer empresa varia de acordo com os critérios adotados, os objetivos da pesquisa e principalmente a subjetividade do analista, pois cada qual tem sua convicção a respeito de valor.

Conforme exemplifica Damodaran (2009, p. 1): "Toda avaliação contém três pontos importantes. O primeiro é o princípio da parcimônia, que estabelece em essência que, para avaliar um bem, não sejam utilizados mais dados do que os absolutamente necessários. O segundo é o equilíbrio entre os benefícios adicionais gerados pela inclusão de um número maior de dados e os custos (e erros) resultantes de tal acréscimo. O terceiro é que quem avalia a empresa não é o modelo - é você. Em um mundo onde o maior problema da avaliação, em geral, não está na falta, mas no excesso de informações, a identificação dos aspectos relevantes é quase tão importante quanto as técnicas e modelos utilizados para avaliar uma empresa".

Nessa perspectiva, inicialmente, almejou-se comparar o Sistema Cooperativo a outras instituições tradicionais, porém a cooperativa, como uma instituição financeira diferenciada, tem restrições e particularidades que por si só não necessitariam de um elemento contrastivo para comprovar o argumento inicial, ou pouco contribuiria para a explanação do objetivo deste artigo: verificar se uma empresa modelo de cooperativismo pode ser estudada por meio de indicadores tradicionais.

Para se entender o processo de investimento em uma cooperativa, é necessário conhecer como se estrutura o capital e como são os processos envolvidos no fornecimento de crédito dessa instituição, como, por exemplo, de onde vêm os recursos necessários para a concessão do crédito. Ressalta-se a interferência das quotas que, além de responsáveis pela eficiência, atuam no funcionamento da cooperativa da seguinte forma:
Figura 1: Funcionamento do Sistema Cooperativo Fonte: Autoria própria

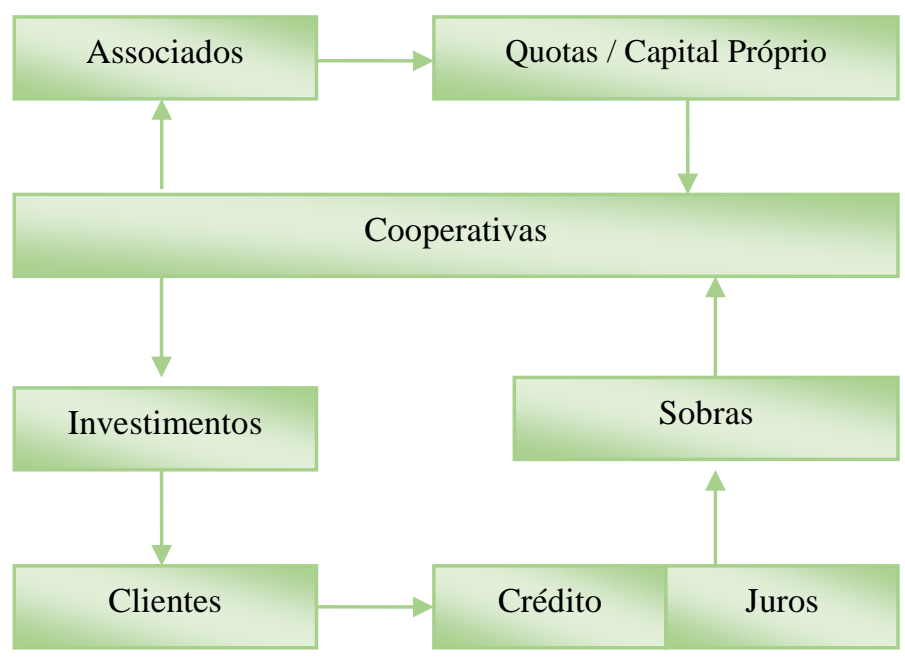

Pode-se atribuir que a forma de captação de recursos das cooperativas afiliadas ao Sistema Sicredi inicia-se pela proximidade com o futuro cooperado, uma vez que este, antes de se associar, deve primeiramente se identificar com os objetivos da cooperativa.

Os associados compõem os recursos próprios, o capital da cooperativa. Captados os recursos, ela estará apta a fornecer crédito para clientes ou para os próprios associados, para dar início ou continuidade a investimentos próprios, como o comércio ou a agricultura. Esses empréstimos têm taxas, como em qualquer outra instituição financeira; esses juros, quando incorporados pela cooperativa, compõem o lucro, ou as sobras que são repassadas aos associados ao final do exercício.

Procedeu-se uma análise dos indicadores de solvência, de rentabilidade, de nível de endividamento e de estrutura de capital do Sistema Sicredi, nos exercícios de 2012 a 2014, para verificar se sua estrutura de capital e se seus serviços financeiros apresentaram crescimento ou melhora nos últimos anos. O cálculo desses indicadores será detalhado na próxima seção.

\subsection{Indicadores}

Permeando-se por esse método singular de intermediação financeira cooperativista, estudou-se, então, por meio de pesquisas bibliográficas, o balanço patrimonial consolidado e os indicadores de solvência, de rentabilidade, de nível de endividamento e de estrutura de capital do Sistema Cooperativo Sicredi nos exercícios de 2012 a 2014. 
Para o cálculo dos indicadores relatados, utilizouse o saldo das contas das demonstrações financeiras consolidadas do Sistema Sicredi, conforme a fórmula de cada indicador (expostas adiante). Para definir os indicadores de liquidez e solvência, de análise de capital, dos índices básicos de rentabilidade, spread e eficiência, e de endividamento utilizados, considerouse o objetivo da pesquisa. Vale ressaltar que a utilização de critérios como a análise da estrutura de capital e os indicadores de desempenho é também defendida por Assaf Neto (2012), um dos raros autores que abrangem as idiossincrasias apresentadas pelas instituições financeiras de modo geral.

\subsubsection{Análise de liquidez e solvência}

Um dos principais objetivos desses indicadores é medir a capacidade de pagamento a curto e a longo prazo das exigibilidades da Instituição, sendo a liquidez $\mathrm{o}$ indicador que reflete a capacidade financeira da instituição em atender prontamente toda a demanda por recursos de caixa, e a solvência é o indicador que evidencia os ativos de risco em nível adequado a dinâmica dos negócios.

Conforme Braga (2013, p. 29), Matarazzo (2010, p. 99-110) e Assaf Neto (2012, p. 303-305) descrevem: os índices de liquidez imediata representam a capacidade de pagamento a curto prazo, enquanto os indicadores de solvência consideram o pagamento a longo prazo.

Diante do exposto, nos anos de 2012, 2013 e 2014, o Sicredi apresentou os seguintes valores:

Tabela 1: Indicadores de liquidez e solvência

\begin{tabular}{lccc}
\hline \multirow{2}{*}{ Indicador } & \multicolumn{3}{c}{ Ano } \\
\cline { 2 - 4 } & 2014 & 2013 & 2012 \\
\hline $\begin{array}{l}\text { Encaixe } \\
\text { voluntário }\end{array}$ & $11 \%$ & $10 \%$ & $9 \%$ \\
\hline $\begin{array}{l}\text { Liquidez } \\
\text { imediata }\end{array}$ & $\mathrm{R} \$ 2,65$ & $\mathrm{R} \$ 2,44$ & $\mathrm{R} \$ 2,30$ \\
\hline $\begin{array}{l}\text { Índice } \\
\text { Empréstimos / } \\
\text { Depósitos }\end{array}$ & 1,19 & 1,14 & 1,12 \\
\hline $\begin{array}{l}\text { Capital de Giro } \\
\text { Próprio }\end{array}$ & $-\mathrm{R} \$$ & $-\mathrm{R} \$$ & $-\mathrm{R} \$$ \\
\hline
\end{tabular}

Fonte: Autoria própria

De acordo com o cálculo do encaixe voluntário (saldo de Disponibilidades dividido pelos Depósitos à vista), as cooperativas do Sistema são capazes de cobrir saques contra os depósitos à vista, em média de $10 \%$, ou seja, ela só teria condições de liberar $10 \%$ de suas disponibilidades para saques, uma vez que $90 \%$ estão comprometidas em aplicações mais rentáveis de empréstimos e de financiamentos. Com esse índice, é possível destacar o quanto a instituição está segura financeiramente, pois essas disponibilidades liberadas para saque não produzem rendimentos e acabam sendo reduzidas para absorverem melhor o impacto de mercado.

Quanto ao índice de Liquidez Imediata (soma das Disponibilidades e Aplicações Interfinanceiras de Liquidez divididas pelo saldo de Depósitos à vista), pode-se dizer que o Sicredi tem em média 2,03 reais para liquidar 1,00 real de depósito à vista e, segundo o critério para a avaliação desse índice (SILVA, 2012), maior que 1 é favorável, por isso o Sicredi mantém recursos para cobrir integralmente depósitos à vista.

Dentre os quatro índices, a relação entre os Empréstimos e os Depósitos (dado pela divisão do saldo de Operações de Crédito pelo saldo de Depósitos) é a que melhor identifica o fornecimento de crédito, porque, grosso modo, revela que o Sicredi concedeu crédito de 1,15 reais em média para cada 1,00 real de recursos captados pela instituição em forma de depósitos.

Por fim, quanto ao Capital de Giro Próprio (Patrimônio Líquido menos Ativo Não Circulante), pode-se considerar que, como o capital de uma cooperativa é formado pelas cotas dos associados e seu patrimônio está diretamente ligado ao ativo circulante, uma vez que acaba sendo sua principal fonte na composição das origens dos recursos do exercício, o Patrimônio Líquido não tem relevância no Imobilizado da cooperativa, por isso o capital de giro próprio apresenta valores negativos.

\subsubsection{Análise de Capital}

A partir desse grupo de índices de estrutura de capital, é possível analisar a composição das fontes de financiamento dos Ativos da empresa. Dada à capilaridade do Sistema Cooperativo, no qual o cliente é ao mesmo tempo fornecedor e dono do negócio, esse grupo fundamenta a importância de uma distribuição dos recursos, conforme exposto na Tabela 2: 
Tabela 2: Análise de capital do Sistema Sicredi

\begin{tabular}{llll}
\hline \multirow{2}{*}{ Indicador } & \multicolumn{2}{c}{ Ano } & \\
& 2014 & 2013 & 2012 \\
\hline Interdependência Financeira & $14 \%$ & $14 \%$ & $14 \%$ \\
\hline Leverage & 6,90 & 7,24 & 7,15 \\
\hline Relação Capital/Depositantes & $45 \%$ & $45 \%$ & $47 \%$ \\
\hline Imobilização Capital Próprio & $13 \%$ & $13 \%$ & $13 \%$ \\
\hline
\end{tabular}

Fonte: Autoria própria.

A alavancagem ou leverage, que corresponde à divisão do Ativo Total pelo Patrimônio Líquido, denota a capacidade da instituição em multiplicar sua rentabilidade por meio do endividamento, considerando os riscos iminentes a essa técnica, principalmente os riscos operacionais (ASSAF NETO, 2012, p. 307).

O endividamento da cooperativa diz respeito aos recursos vindos de outros fornecedores que não integram a relação "associado-fornecedor-dono". Por esse prisma, o grau de alavancagem (ou leverage) por meio de endividamento é consideravelmente pequeno.

Ao calcular a Imobilização do Capital Próprio do Sicredi pela divisão do Ativo Permanente pelo Patrimônio Líquido, obtém-se $13 \%$, evidenciando, dessa forma, que o Sistema usufrui de $87 \%$ de recursos de terceiros para manutenção dos negócios, destacando novamente que o Patrimônio Líquido não apresenta um alto grau de significância na composição do Imobilizado.

\subsubsection{Análise Básica de Rentabilidade}

Os indicadores expostos a seguir referem-se ao potencial do sistema cooperativo em gerar resultados econômicos. Por meio das Demonstrações de Resultado dos exercícios de 2012, 2013 e 2014, observa-se que a junção dos ativos gera receitas e, por consequência, o lucro:

Tabela 3: Indicadores básicos de rentabilidade do Sistema Sicredi

\begin{tabular}{llllll}
\hline \multirow{2}{*}{ Indicadores } & & \multicolumn{3}{c}{ Ano } \\
\cline { 3 - 5 } & & 2014 & 2013 & 2012 \\
\hline $\begin{array}{l}\text { Retorno sobre } \\
\text { Líquido }\end{array}$ & o & Patrimônio & $19 \%$ & $17 \%$ & $17 \%$ \\
\hline Retorno Investimento Total & $3 \%$ & $2 \%$ & $2 \%$ \\
\hline
\end{tabular}

Fonte: Autoria própria.

O ROE (Return on Equity), ou Retorno sobre o Patrimônio Líquido, dado pela divisão do Lucro
Líquido pelo Patrimônio Líquido, aponta o poder de ganho dos proprietários (associados) da Sicredi, pois para $\mathrm{R} \$ 1,00$ investido ela retornaria uma média de $\mathrm{R} \$ 0,17$ centavos para seus investidores, logo levariam cinco anos para ter de volta seu 1 real. Coincidentemente, conforme o Relatório Consolidado de 2014, o capital social do Sistema Sicredi é dividido em quotas-partes de valor unitário equivalente a $\mathrm{R} \$ 1,00$, sendo que cada associado tem direito a um voto, independentemente do número de suas quotaspartes, portanto pode-se afirmar que os investidores obtiveram um retorno de $\mathrm{R} \$ 0,19$ (19\%) por cota em 2014.

O lucro é redistribuído para os associados no final de cada exercício, proporcionalmente à participação de cada um, como também constitui a reserva do Fundo Garantidor, conforme Faria (2014, p. 1): "É um dos mecanismos da rede de proteção do sistema financeiro, cujos instrumentos são utilizados preventivamente para evitar o risco sistêmico a partir da redução do risco de crises localizadas. Essa rede de proteção envolve também regulação prudencial, supervisão eficiente, legislação adequada, práticas adequadas de gestão e metodologias adequadas de contabilidade e de transparência na divulgação de informações à população".

Por conta disso, o ROI (Return on Investment), ou Retorno sobre os Investimentos (Lucro Líquido dividido pelo Ativo Total), que mede a eficácia da gestão dos recursos ativos disponíveis na geração de lucro, tem sua interpretação básica de "quanto maior melhor" invalidada, quando se trata de uma cooperativa, uma vez que seu objetivo maior não é a geração de lucro.

\subsubsection{Análise de Rentabilidade, Spread e Eficiência}

Nas instituições financeiras, entre elas as cooperativas, os benefícios econômicos oriundos dos recursos aplicados no ativo geram as chamadas "receitas da intermediação financeira", enquanto os valores registrados no passivo ocasionam "despesas com intermediação financeira". Assaf Neto (2012, p. 302) atribui a diferença entre estas receitas e as despesas ao spread da instituição. Desta forma, o Sistema Sicredi apresentou os seguintes números: 
Tabela 4: Rentabilidade, spread e eficiência do Sistema Sicredi

\begin{tabular}{|c|c|c|c|}
\hline \multirow{2}{*}{ Indicadores } & \multicolumn{3}{|c|}{ Ano } \\
\hline & 2014 & 2013 & 2012 \\
\hline Margem Líquida & $19 \%$ & $18 \%$ & $18 \%$ \\
\hline Margem Financeira & $8 \%$ & $7 \%$ & $8 \%$ \\
\hline Custo Médio de Captação & $12 \%$ & $10 \%$ & $10 \%$ \\
\hline $\begin{array}{l}\text { Retorno Médio das Operações de } \\
\text { Crédito }\end{array}$ & $29 \%$ & $26 \%$ & $27 \%$ \\
\hline Lucro dos Ativos & $14 \%$ & $13 \%$ & $14 \%$ \\
\hline
\end{tabular}

Fonte: Autoria própria.

A margem líquida compara o lucro líquido em relação ao montante de receitas de intermediação financeira do período analisado, apresentando assim o percentual de lucratividade obtido pela empresa (DAMODARAN, 2009).

Mesmo que a intenção ou propósito cooperativo não seja lucrar, essa margem representa também um desenvolvimento do cooperado que, por sua vez, é o principal beneficiário das sobras (lucro).

A margem financeira dos ativos é a relação entre o resultado bruto de intermediação financeira e o total do ativo da instituição. Vale ressaltar também que a instituição teve uma frequência alta no volume de vendas (receitas), ao mesmo passo em que o lucro líquido aumentou, por isso a margem manteve-se estável.

O custo médio de captação, expresso pela divisão entre as Despesas Financeiras de Captação de Mercado e as Operações de Crédito, é de aproximadamente $11 \%$. Isso revela que o Sistema Sicredi tem um baixo custo financeiro do capital investido na instituição pelos poupadores. Uma vez que estes representem também o dono da instituição, não é interessante que o custo seja alto.

O retorno médio das operações de crédito (relação entre as receitas financeiras provenientes das operações de crédito e o valor médio aplicado em créditos) é de $27 \%$. A lucratividade dos ativos apresenta a relação entre as receitas de intermediação financeira e o total dos ativos, isto é, a porcentagem do total investido que gerou receitas financeiras.

\subsubsection{Análise de Endividamento}

De acordo com Damodaran (2009, p. 52-53), os índices de endividamento procuram determinar a capacidade de a empresa saldar o principal, isto é, a diferença entre o montante e os juros. Esses indicadores também mensuram o autofinanciamento da empresa, que aumenta o poder de negociação em face de terceiros, pois é uma fonte gratuita de fundos, minimiza o recurso a fundos externos e permite uma maior flexibilidade na tomada de decisões de investimento. Por essa perspectiva, o Sistema Sicredi apresentou os seguintes indicadores:

Tabela 5: Indicadores de endividamento do Sistema Sicredi

\begin{tabular}{llll}
\hline & \multicolumn{3}{c}{ Ano } \\
\cline { 2 - 4 } Indicadores & 2014 & 2013 & 2012 \\
\hline $\begin{array}{l}\text { Capital de Terceiros em relação aos } \\
\text { recursos totais }\end{array}$ & $85 \%$ & $86 \%$ & $86 \%$ \\
\hline $\begin{array}{l}\text { Garantia de Capital Próprio } \\
\text { relação ao Capital de Terceiros }\end{array}$ & $17 \%$ & $16 \%$ & $16 \%$ \\
\hline Composição do Endividamento & $50 \%$ & $53 \%$ & $55 \%$ \\
\hline
\end{tabular}

Fonte: Autoria própria.

A composição do endividamento é calculada por meio da divisão do Passivo Circulante e do Passivo Total. Quanto menor o índice, melhor a composição do endividamento das cooperativas. Observa-se que, de 2012 a 2014, o Sicredi tem diminuído aos poucos o endividamento, o que indica a diminuição no volume das dívidas de curto prazo em relação às dívidas totais do Sistema. Ao diminuir sua composição do endividamento, o Sistema Sicredi desenvolve uma maior capacidade de geração de capital de giro.

Para o índice de Capital de Terceiros em relação aos recursos totais, pode-se concluir que, como a maior parte dos recursos captados são as cotas dos associados, estes somam ao montante do capital de terceiros em média $86 \%$. Devido a isso a política de "quanto menor melhor" não se aplica a uma cooperativa. O inverso ocorre com o índice de Garantia de Capital Próprio em relação ao Capital de Terceiros, pois parte do Patrimônio é composta de capitais de terceiros, os associados.

Quanto à Composição do Endividamento, está equilibrada, pois seu Passivo Circulante e Passivo Não Circulante podem ser divididos em média de $50 \%$. Em outras palavras, o montante que a empresa deve em curto prazo é igual ao que deve em longo prazo. 
Dessa forma, constata-se que a análise dos indicadores está atrelada aos aspectos cooperativistas, dentre outras conclusões expostas na próxima seção.

\section{Conclusões}

Estudar a estrutura de capital do Sistema Sicredi permitiu a compreensão analítica da composição monetária de um sistema e os reflexos do funcionamento operacional da cooperativa nos indicadores financeiros.

Com a revisão bibliográfica, observou-se que as cooperativas apresentam maior flexibilidade na gestão devido à proximidade com o cooperado, e por meio de sua estrutura de capital ou forma de captação e alocação dos recursos foi comprovado o crescimento da margem de rentabilidade sob os empréstimos concedidos.

Existem algumas dificuldades para estudar o comportamento das finanças de uma cooperativa, pois esta, enquanto instituição financeira, não faz diferenciação clara entre seus ativos e passivos, dada a relação e a interferência das cotas de capital e o grande percentual de seus deveres (passivo), que pode ser emprestado e que, dessa forma, pode gerar receitas (ativo).

Foi possível verificar que a interpretação de alguns indicadores (como o Return On Equity) é contrária quando se trata de cooperativas, uma vez que o patrimônio não é propriedade exclusiva da Instituição, sendo dividido com os cooperados. Porém, ainda é possível usufruir de análises tradicionais para cálculos como capacidade de pagamento e perfil de dívidas.

Observou-se que, de fato, as cooperativas apresentam crescimento contínuo em seu patrimônio, consequência do aumento do número de pessoas que aderem às causas cooperativistas, influenciando também sua capacidade de pagamento, uma vez que os indicadores utilizados para calcular a eficiência do Sistema Cooperativo demonstraram que a instituição apresenta um percentual de disponibilidades suficiente para liquidação de seus compromissos correlatos a depósitos dos clientes.

Como já mencionado, neste artigo optou-se por não comparar o cooperativismo a outras instituições financeiras, discorrendo-se apenas sobre a singularidade cooperativa na captação de recursos. Os assuntos abordados neste artigo não representam toda a complexidade do assunto, portanto recomenda-se novos estudos sobre o impacto das singularidades de operações de uma cooperativa em diferentes perspectivas de mercado.

Além do mais, após tomar ciência dos indicadores e de seus reflexos dentro do Sicredi, colocou-se de lado alguns mitos e desconfianças sobre a garantia e a segurança financeira de uma cooperativa de crédito, pois é um dos meios de captação e de alocação de recursos pouco divulgado e muitas vezes, pouco conhecido.

\section{Agradecimentos}

Aos orientadores deste artigo, Prof. Dr. Luzimar Goulart Gouvêa, Prof. Me. Benedito Luciano Antunes de França e Prof. Me. Renald Antônio Franco de Camargo, pelo desafio e total apoio. A Tobias Sirianni Melo, pela cumplicidade e confiança. Aos que desconheciam a relevância deste tema, que nos motivaram a lutar por essa causa.

\section{Referências}

ASSAF NETO, Alexandre. Estrutura e análise de balanços: um enfoque econômico-financeiro: comércio e serviços, indústrias, bancos comerciais e múltiplos. 10ª . ed. São Paulo: Atlas, 2012. p. 303-324.

BRAGA, Roberto. Fundamentos e Técnicas de Administração Financeira. 21 ${ }^{\mathrm{a}}$. reimp. São Paulo: Atlas, 2013. p. 29-30.

BRASIL. Congresso. Senado. Lei $\mathrm{n}^{\mathrm{o}}$ 4.595, de 31 dezembro de 1964. Diário Oficial da União, Poder Legislativo, Brasília, DF, 31 dez. 1964. Seção 1, p. 28. (Lei da Reforma Bancária). Disponível em: <http://www.planalto.gov.br/ccivil_03/leis/L4595. htm>. Acesso em: 12 jun. 2015.

BRASIL. Congresso. Senado. Lei $\mathrm{n}^{\circ}$ 5.764, de 16 dezembro de 1971. Diário Oficial da União, Poder Legislativo, Brasília, DF, 16 dez. 1971. Seção 1, p. 10354. (Lei do Cooperativismo). Disponível em: <http://www.planalto.gov.br/ccivil_03/leis/l5764.h $\mathrm{tm}>$. Acesso em: 27 mar. 2015.

CARDOSO, Univaldo Coelho (ORG.). Cooperativa. Brasília : SEBRAE, 2014. (Série: Empreendimentos Coletivos) 62 p. Disponível em: <http://www.sebraesp.com.br/arquivos_site/bibliot 
eca/guias_cartilhas/empreendimentos_coletivos_c ooperativa.pdf>. Acesso em: 13 abr. 2015.

DAMODARAN, Aswath. Avaliação de Investimentos: Ferramentas e técnicas para a determinação do valor de qualquer ativo. Trad. Kleber Nunes. Rev. Eduardo Fortuna e José Rabello Moraes. 2a . ed. Rio de Janeiro : Qualitymark, 2009 . p. 1-215.

FARIA, Lúcio César de. O fundo garantidor do cooperativismo de crédito. In: MEINEN, EEnio; PORT, Márcio. Cooperativismo financeiro: percurso histórico, perspectivas e desafios. Manaus: Confebras, 2014. p. 529-549 (capítulo $\left.11^{\circ}\right)$

FARIA, Lúcio César de; et al. Relatório Anual 2014: Fundo Garantidor do Cooperativismo de Crédito (FGCoop). Brasília/DF: FGCoop, 2015.

FUNDAÇÃO SICREDI. A Trajetória da Sicredi. Cartilha Institucional. Porto Alegre: Fundação Sicredi, 2010.

MATARAZZO, Dante Carmine. Análise Financeira de Balanços: abordagem gerencial. $7^{\text {a }}$. ed. São Paulo: Atlas, 2010.

MATIAS, Alberto Borges; et al. Bancos versus cooperativas de crédito: um estudo dos índices de eficiência e receita da prestação de serviços entre 2002 e 2012. RAM - Revista de Administração Mackenzie, Universidade Presbiteriana Mackenzie, São Paulo: vol. 15, n. 5, p. 195-223, out. 2014. Disponível em: <http://editorarevistas.mackenzie.br/index.php/RA M/article/view/6701> Acesso em: 25 mar. 2015.

PINHEIRO, Marcos Antonio Henriques. Cooperativas de crédito: história da evolução normativa no Brasil. $6^{a}$ ed. Brasília: BACEN, 2008.

PIZZANI, Luciana; et al. A arte da pesquisa bibliográfica na busca do conhecimento. Revista Digital de Biblioteconomia e Ciência da Informação, Universidade de Campinas, Campinas: vol. 10, n.1, p. 53-66, jul./dez. 2012.
RECEITA FEDERAL. Perguntas Frequentes: Qual a diferença entre sobras líquidas e resultado do exercício apurados pelas sociedades cooperativas?. $2005 . \quad$ Disponível em: <http://www.receita.fazenda.gov.br/PessoaJuridic a/DIPJ/2005/PergResp2005/pr652a653.htm>.

Acesso em: 12 jun. 2015.

SERVIÇO BRASILEIRO DE APOIO ÀS MICRO E PEQUENAS EMPRESAS. Gestão de Cooperativas de Crédito: $O$ cooperativismo de crédito. SEBRAE: 2010. (Módulo 1: Curso à distância desenvolvido pela plataforma EADSEBRAE, com carga-horária de 30 horas).

SILVA, José Pereira de. Análise financeira das empresas. $11^{a}$ ed. São Paulo: Atlas, 2012.

SISTEMA SICREDI. Demonstrações Financeiras consolidadas: 31 dezembro de 2013. 2014. Disponível em: <https://www.sicredi.com.br/html/conheca-osicredi/relatorios/arquivos/demons tracoes_financeiras_combinadas_2013.pdf> . Acesso em: 23 mar. 2015.

Demonstrações Financeiras consolidadas: 31 dezembro de 2014. 2015a. Disponível em: <https://www.sicredi.com.br/html/conheca-osicredi/relatorios/arquivos/demonstra coes_financeiras_combinadas_2014.pdf>. Acesso em: 23 mar. 2015, às 14h20min.

Sustentabilidade 2014: Sistema Sicredi. Superintendência de Marketing e Canais: 2015 b. (Comunicação Institucional). Disponível em: <https://www.sicredi.com.br/html/conheca-osicredi/sustentabilidade/>. Acesso em: 23 mar. 2015.

SMITH, Adam. A Riqueza das Nações. Trad. Luiz João Baraúna. São Paulo : Nova Cultural, 1996. (Série: Os Economistas. Título Original: An Inquiry into the Nature and Causes of the Wealth of Nations).

SOARES, Marden Marques; MELO SOBRINHO, Abelardo Duarte de. Microfinanças: O papel do Banco Central do Brasil e a importância do 
cooperativismo de crédito. $2^{\mathrm{a}}$ ed. rev. e ampl. Brasília : BACEN, 2008.

SOARES, Marden Marques; BALLIANA, Gilson Marcos. O cooperativismo de crédito no Brasil. In: Governança Cooperativa: Diretrizes e mecanismos para fortalecimento da governança em cooperativas de crédito. Brasília: BACEN, 2009. p. 17-30 (Capítulo $1^{\circ}$ ).

WILDE, Oscar. O retrato de Dorian Gray. Trad. Marcella Furtado. São Paulo : Landmark, 2012. Capítulo 1, p. 39. (Ano de publicação original: 1890. Título original: The Picture of Dorian Gray). 
